\title{
Innovative pneumatic device for combined seeding of various tilled crops
}

\author{
Yuri Lachuga ${ }^{1}$, Badri Akhalaya ${ }^{2}$, Yuri Shogenov ${ }^{1}$, Besarion Meskhi $^{3}$, Dmitry Rudoy ${ }^{3 *}$, and \\ Anastasiya Olshevskaya ${ }^{3}$ \\ ${ }^{1}$ Russian Academy of Sciences (RAS), Russian Federation, 119334, Moscow, Leninskyave., 32a \\ ${ }^{2}$ Federal Scientific Agroengineering Center VIM, Russian Federation, 109428, Moscow, 1st \\ Institutskyave., 5 \\ ${ }^{3}$ Don State Technical University, Gagarin sq., 1, Rostov-on-Don, 344003, Russia
}

\begin{abstract}
For sowing seeds of agricultural crops, the industry produces seeding devices of various modifications, these include seeding devices of pneumatic seeders, operating both on excess air pressure and on vacuum. The design we have developed belongs to the second group. The purpose of current work is to create a pneumatic sowing device operating in a vacuum, capable of sowing seeds of row crops and forage crops in a combined and nesting way in compliance with established seeding patterns and rates.
\end{abstract}

\section{Introduction}

The analysis of the existing pneumatic seeding devices, consisting of a hopper for seeds, with two vacuum chambers, a metering device and a coulter, is carried out.

Some of them have the following disadvantages:

- the dosing device is too massive, requiring a lot of material;

- the constructive design feature does not allow sowing seeds of two crops in one row in compliance with agricultural requirements;

- a large percentage of seed damage due to the lack of a pneumatic system for removing excess seed;

- seeds fall into the furrow by its own weight, which reduces the performance of seeding unit;

- seeds sown in a combined method are not placed at different sowing depths, which cannot be allowed due to agricultural requirements. [1-3]

Other known devices have several disadvantages: a) the device does not sow seeds in a nesting way with a different number of seeds per nest, as well as a different seeding pattern;

* Corresponding author: dmitriyrudoi@gmail.com 
б) to adjust the seeding pattern by changing the number of holes on the seeding disc, it must be replaced, with the required number of holes.[4]

\section{Materials and methods}

Pneumatic sowing device for combined sowing of seeds of two crops (Fig. 1) contains a seed hopper 1 , consisting of two parts with partition 2 , duct 3 , vacuum chamber 4 , coulter 5 , dispenser 6 with holes 7 . The sowing discs of the metering device are installed on axles 8 , which are connected by a sleeve 9 , tedder 10 , chain drive 11 .
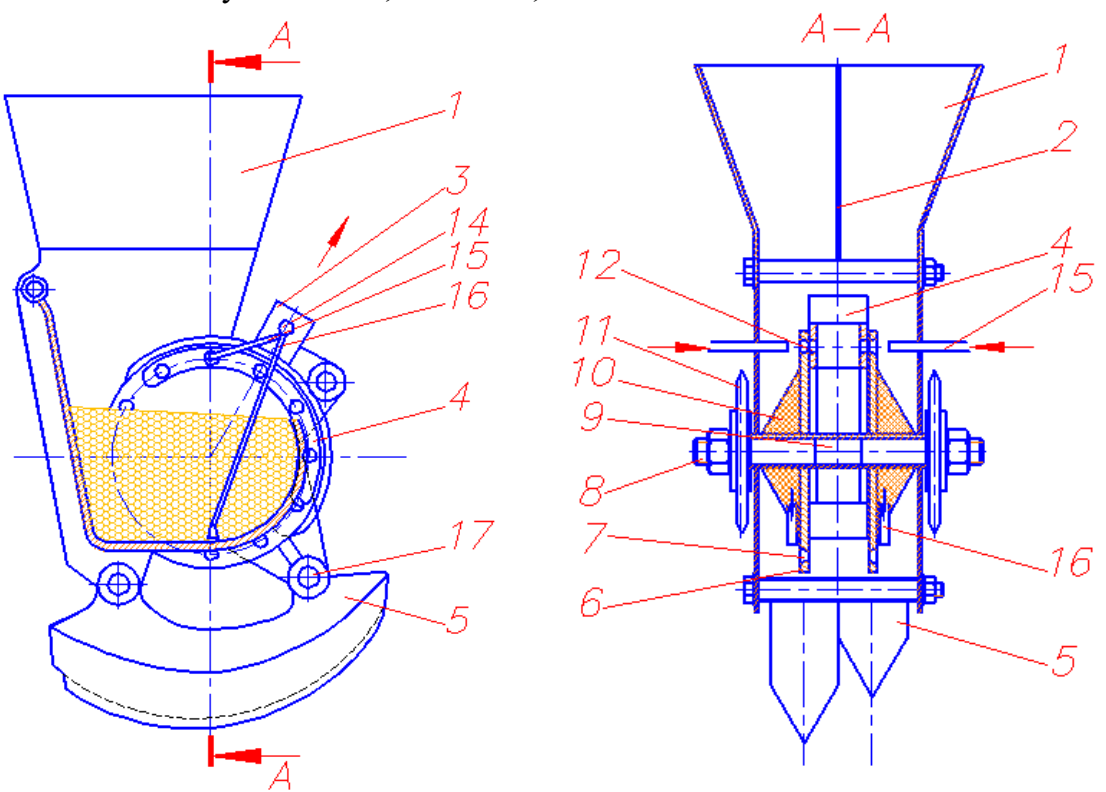

Fig. 1. Pneumatic sowing device for combined sowing of seeds of two crops, in two projections

The vacuum chamber 4 (Fig. 2) is arcuate, on the sides with slots 12 , which help create a vacuum and suck 6 seeds of two different crops to the cells 7 of the metering device from different sides of the arc. Cells (holes) 7 are threaded. From the outside, the air duct 3 has two nozzles 14, which are located at one end in the air duct 3 and are directed to meet the movement of the air flow. There are two such branch pipes for each seeding disc separately. 


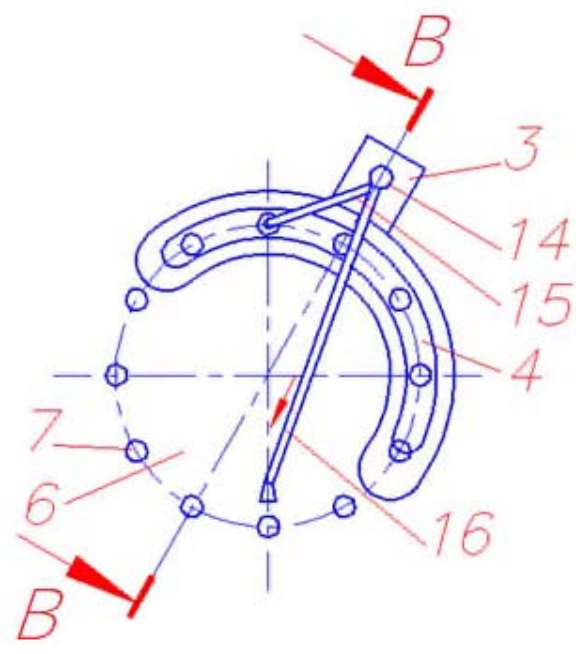

a

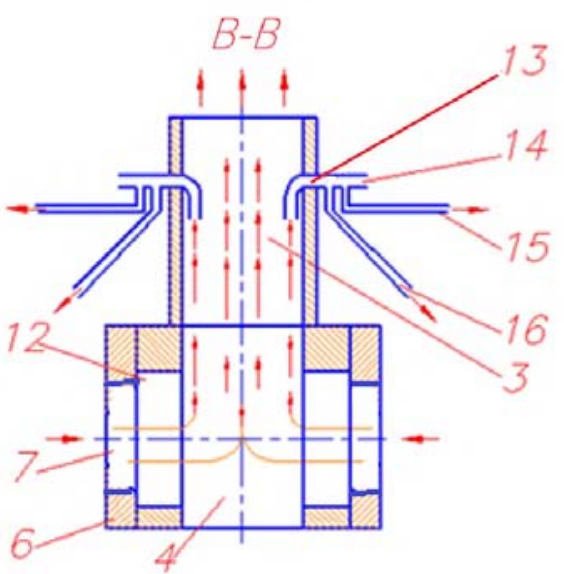

b

Fig. 2. a - vacuum chamber, general view, b - section B - B

The outer side of each branch pipe 14 is provided with two sleeves 15 and 16 having different sections. The first 15 cut off the extra seeds pressed to the cells 7 . The second 16 are located at the bottom of the seeding discs at an angle of 6-80 to the vertical axis towards the movement of the seeding unit. With the help of the sleeve 16, the air flow, removing the seed that has sucked to the cell, towards the furrow, gives it acceleration, which contributes to an increase in the forward speed of the seeding unit and to increase the yield. The coulter is mounted on two axles 17.

Bushings 18 with different numbers of holes 19 are screwed onto the cells of the seeding disc (Fig. 3). For row crops, the number of holes on the bushings is at least three, and the ratio of the seeding disc thickness 6 to the bushing diameter is 1:3. For forage crops, the number of holes on the bushings is at least no more than six, and the ratio of the seeding disc thickness to the bushing diameter is $1: 4$. In this case, it is possible to sow seeds in dotted, combined and nested ways.[5-7]
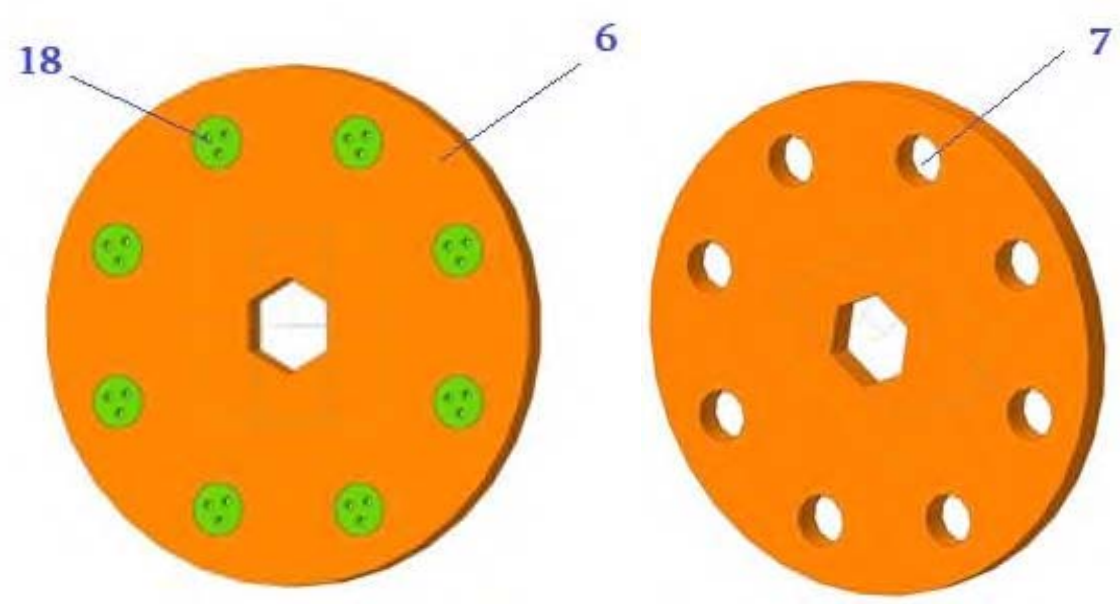
Fig. 3. Sowing disc a - with screwed-in bushings; b - without bushings

Such ratios of the seeding disc thickness to the bushing diameter are explained by the fact that with an increase in the bushing diameter, it is necessary to increase the seeding disc thickness, since in order to securely fix the bushing in the seeding disc bore, it is necessary to increase the number of threads with the required pitch. For example, it has been experimentally found that for row crops with a disc thickness of 6 $\mathrm{mm}$ and a sleeve diameter of $18 \mathrm{~mm}$, the ratio of these parameters will be $1: 3$, i.e. the thickness of the disc depends on the diameter of the sleeve. Similarly for forage crops, with a disc thickness of $4 \mathrm{~mm}$ and a sleeve diameter of $16 \mathrm{~mm}$, the ratio will be 1:4. [812]

The diameter of the sleeve depends on the parameters of the seeds of the sown crop, for example, for sowing corn seeds in the amount of 2 or 3 pieces, it is necessary that the diameter of the sleeve with 3 holes is $18 \mathrm{~mm}$ (one hole is needed for one seed), if the diameter of the sleeve is less than $18 \mathrm{~mm}$, then corn seeds in the amount of 3 pieces will fit if it is no longer advisable. Figure 4 shows sleeves for seeding discs with different numbers of holes and - a blind sleeve.[13-17]

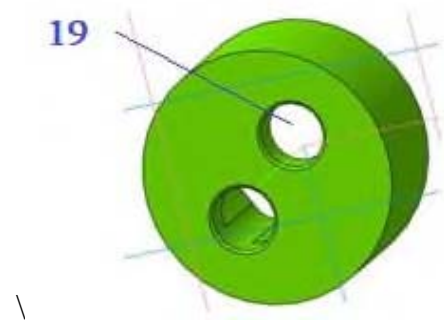

a

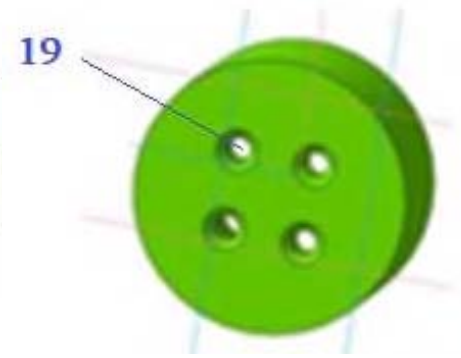

discs, a - with a different number of holes

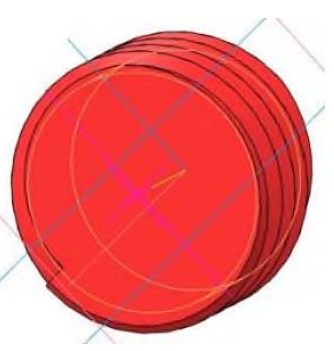

b

Fig. 4. Bushings for seeding discs, $a$ - with a different number of holes and $b-a$ blind bushing

For planting seeds of two crops at different depths, the seeding device is equipped with a two-level opener (Fig. 4.), in which the distance L between the axes is set by the condition $\mathrm{L}=2 \mathrm{a}+\mathrm{b}, \mathrm{mm}$, where $\mathrm{a}$ is the disc thickness, $\mathrm{mm}, \mathrm{b}$ is the width of the vacuum chamber, $\mathrm{mm}$ 


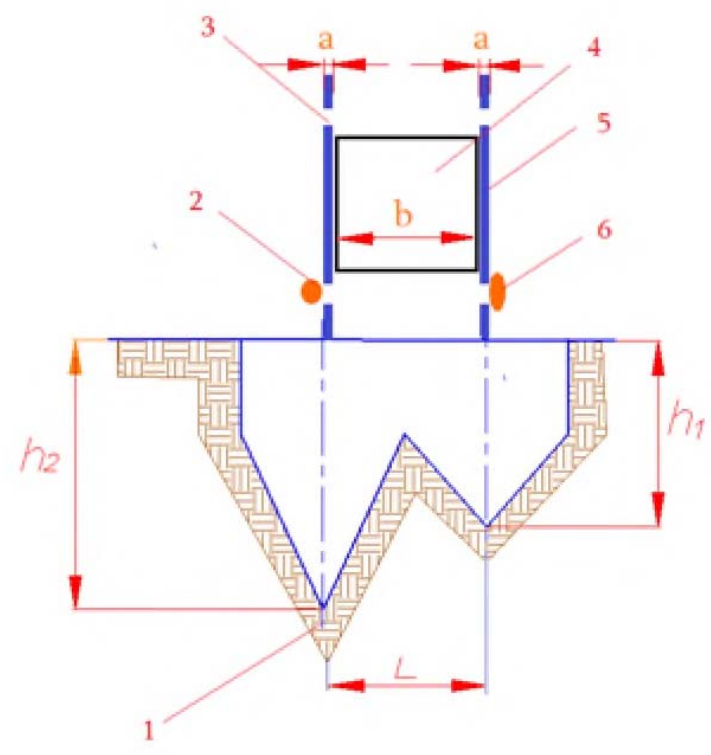

Fig. 4 Scheme of a two-level runner opener, 1 - opener; 2 - seed of one culture; 3 - hole of the seeding disc; 4 - vacuum chamber; 5 - sowing disc; 6 - seed of the second culture

During the movement of the sowing unit, the seeds from the two halves of the seed hopper penetrate into the receiving chamber of the sowing device, individual seeds, when moving down, stick to the holes placed on the bushings, excess seeds are blown away by sleeve 15 . The rotating disk moves the seeds to the seed discharge zone, where they are affected by air flow by sleeve 16, which is installed at an acute angle to the vertical axis of the apparatus in the direction of the movement of the seeding unit. The selected angle was determined so that it would allow when sowing the seeds of two crops simultaneously in two parallel rows, fulfilling the established seeding pattern. For example, if the angle $\alpha>$ $8^{\circ}$, then the seeds after falling will mix forward if $\alpha<6^{\circ}$, then - backwards, which disturbs the order of sowing seeds.[17-23]

The air duct functions in two directions, firstly, it creates a vacuum, and secondly, it ensures the operation of the hoses 15 and 16, using the nozzle 14 built into it.

The removed seed at the bottom of the sowing disc is fed into a two-level skid opener, which places the seeds of the two crops in the furrow at different planting depths.[24]

\section{Conclusions}

The proposed pneumatic sowing device for combined sowing of seeds of two crops allows sowing seeds of row crops and forage crops with the required number for each of them at different planting depths. In the case of sowing seeds of two crops at the same depth, it is necessary to replace the opener with skids with the same seeding depth.

The use of the proposed pneumatic seeding device will expand technical capabilities, increase operational reliability and increase productivity. 


\section{References}

1. Lachuga Yu.F., Shogenov Yu.Kh., Izmaylov A.Y., Lobachevsky Y.P. Scientific and technical products of scientific organizations of agroengineering profile in the conditions of digitalization of the agro-industrial complex // machinery and equipment for the village. 2020. №5 (275). P. 2-9.

2. Izmaylov A.Y., Shogenov Yu.Kh. Intensive machine technologies and equipment of a new generation for the production of main groups of agricultural products // Equipment and equipment for the village. - 2017. - N7(241). - P.2-6.

3. Lobachevsky Y.P., Akhalaya B.Kh., Sizov O.A., Lovkis V.B. Cost-effective environmentally sound method of compacted crops of agricultural crops // Agricultural machines and technologies. - 2015. - N 6. - P.4-8.

4. Abramov, A.M., Yu Klyukin, V., Kozhikin, V.V., Kochneva, O.V. IOP Conference Series: Materials Science and Engineering 939(1),012001 DOI: 10.1088/1757899X/939/1/012001

5. Alshyn Altybayev, Adilbek Zhanbyrbayev, Besarion Meskhi, Dmitriy Rudoy, Anastasiya Olshevskaya, and Anna Prohorova, E3S Web of Conferences 135, 01078 (2019) https://doi.org/10.1051/e3sconf/201913501078.

6. Igor Bozhko, Galina Parkhomenko, Sergey Kambulov, Andrey Boyko, Vladimir Kolodkin, Magomed Magomedov, and Dmitriy Rudoy E3S Web of Conferences 175, 05025 (2020) INTERAGROMASH 2020 https://doi.org/10.1051/e3sconf/202017505025

7. Akhalaya B.Kh. A laboratory study of the pneumatic sowing device for dotted and combined crops // AMA, Agricultural Mechanization in Asia, Africa and Latin America. 2019. - Vol. 50. - N 1. - P. 57-59.

8. Aleksey Zavaliy, Sergey Volozhaninov, Olga Shiian, Dmitriy Rudoy and Anastasiya Olshevskaya E3S Web of Conferences 175, 05003 (2020) INTERAGROMASH $2020 \mathrm{https}$ ://doi.org/10.1051/e3sconf/202017505003

9. Besarion Meskhi, Boris Golev, Victor Efros, Dmitriy Rudoy, Anastasiya Olshevskaya, Viktor Zhurba, Yevgeniy Chayka, E3S Web of Conferences 135, 01083 (2019) ITESE-2019 https://doi.org/10.1051/e3sconf/201913501083

10. Viktor Zhurba, Yevgeniy Chayka, Natalya Gucheva, Dmitry Ushakov, Natia Ugrekhelidze, Natalia Kulikova, and Marina Egyan E3S Web of Conferences 135, 01087 (2019) ITESE-2019 https://doi.org/10.1051/e3sconf/201913501087

11. Vasiliy Chernovolov, Lyudmila Kravchenko, Alla Nikitina and Vladimir Litvinov E3S Web of Conferences 175, 05016 (2020) INTERAGROMASH 2020 https://doi.org/10.1051/e3sconf/202017505016

12. Vladimir Kravchenko, Lyudmila Kravchenko and Viktor Oberemok E3S Web of $\begin{array}{lllll}\text { Conferences } & \mathbf{1 7 5}, & 05017 & \text { (2020) INTERAGROMASH } & 2020\end{array}$ https://doi.org/10.1051/e3sconf/202017505017

13. Ivanov V.V., Popov S.I., Selemeneva E.M., Babazhanov N.T. // XV International scientific-technical conference «Dynamics of technical systems» (DTS-2019): AIP Conference Proceedings, Vol. 2188, pp. 020015, 2019. doi.org/10.1063/1.5138389

14. Ivanov V.V., Popov S.I., Marchenko Ju.V., Marchenko E.V., Dontsov N.S., Timofeev S.A. // XII International Scientific Conference on Agricultural Machinery Industry (INTERAGROMASH 2019): IOP Conference Series: Earth and Environmental Science, Vol. 403, pp. 012115, 2019. doi:10.1088/1755-1315/403/1/012115

15. Korotky A.A., Marchenko E.V., Ivanov V.V., Popov S.I., Marchenko Ju.V., Dontsov N.S. // XII International Scientific Conference on Agricultural Machinery Industry (INTERAGROMASH 2019): IOP Conference Series: Earth and Environmental Science, Vol. 403, pp. 012116, 2019. doi:10.1088/1755-1315/403/1/012116 
16. Starovoitov S.I., Blokhin V.N., Chemisov N.N. On the selection of the ideal soil model / Design, use and reliability of agricultural machines. Collection of scientific papers. Bryansk: Publishing House of the Bryansk State Agricultural Academy, 2011. P.66-70.

17. Lidong Ren, Thijs Vanden Nest, Greet Ruysschaert, Tommy D’Hose, Wim M. Cornelis Short-term effects of cover crops and tillage methods on soil physical properties and maize growth in a sandy loam soil Soil and Tillage Research Volume 192 Sept. 2019 Pages 76-86.

18. Márcio R. Nunes, Eloy A. Pauletto, José E. Denardin, Luis EAS Suzuki, Harold M. van Es Dynamic changes in compressive properties and crop response after chisel tillage in a highly weathered soil Soil and Tillage Research Volume 186 March 2019 Pages 183- 190.

19. Jokar, H., Zeinali, H., Tamaddondar, M.H. 2020 Mathematics and Computers in Simulation 178, c. 439-463 DOI: 10.1016/j.matcom.2020.05.032

20. Xing, H., Wang, Z., Luo, X., He, S., Zang, Y. 2020 Computers and Electronics in Agriculture 178,105697 DOI: 10.1016/j.compag.2020.105697

21. Morris, R.J., Ridgway, B.S., Woodcock, J.P. The use of intermittent pneumatic compression of the thigh to affect arterial and venous blood flow proximal to a chronic wound site. International Wound Journal, 2020, 17(5), c. 1483-1489, DOI: 10.1111/iwj.13418.

22. Abramov, A.M., Yu Klyukin, V., Kozhikin, V.V., Kochneva, O.V., The use of fuzzy logic for the clean-up systems control for bunkers, containing bulk solids. IOP Conference Series: Materials Science and Engineering, 2020, 939(1),012001. DOI: 10.1088/1757-899X/939/1/012001

23. Yevgeniy Chayka, Viktor Zhurba, Natalia Krivtsova, Anna Khadzhidi, Pavel Voshchevoz and Natia Ugrekhelidze E3S Web of Conferences 175, 09007 (2020) INTERAGROMASH 2020 https://doi.org/10.1051/e3sconf/202017509007

24. Andrey Nesmiyan, Lyudmila Kravchenko, Vladimir Khizhnyak and Elena Zubrilina E3S Web of Conferences 175, 05019 (2020) INTERAGROMASH 2020 https://doi.org/10.1051/e3sconf/202017505019 